\title{
Perspectiva Evolucionária na Teoria Social Crítica de Habermas ${ }^{1}$
}

\author{
Clodomiro José Bannwart Júnior²
}

\begin{abstract}
RESUMO: Busca-se acompanhar o desenvolvimento da teoria evolucionária no pensamento de Habermas, a partir da afirmação colhida no prólogo de Problemas de Legitimação do Capitalismo Tardio, de 1973: "O caráter programático evidencia que uma teoria da evolução social hoje se encontra apenas esboçada, mas que, no entanto, deveria constituir a base da teoria da sociedade". A atençáo é direcionada à forma como Habermas reorienta o sentido evolucionário do desdobramento histórico à luz do conceito de mundo da vida, como esfera de realização da ação comunicativa. Objetiva-se investigar como é projetada nesse modelo de ação, por meio da linguagem, a tarefa de produção e reprodução simbólica do consenso normativo entre os participantes do mundo social, ao mesmo tempo em que Habermas sinaliza haver um telos de integraçáo social imanente à própria prática comunicativa. Nesse sentido, procurar-se-á demonstrar que, assim como a pragmática universal serve de base teórica para a análise de processos de distorção da linguagem e de socialização anormais, a teoria da evolução social serve de parâmetro para uma teoria social crítica com intenção emancipatória de avaliar o desdobramento empírico e contingente da dinâmica histórica.
\end{abstract}

PALAVRAS-CHAVE: Evolução social. Ação comunicativa. Integração social. Teoria social.

No prólogo de Problemas de Legitimação do Capitalismo Tardio (1973), situa-se uma primeira e forte manifestação que vincula a teoria da evolução social à teoria da sociedade. "O caráter programático evidencia que uma teoria da evoluçấo social hoje encontra-se apenas esboçada, mas que, no entanto, deveria constituir a base da teoria da sociedade." (HABERMAS,

\footnotetext{
${ }^{1}$ Trabalho apresentado no $3^{\circ}$ Colóquio Habermas: Modernidade, Linguagem e Política, realizado no período de 17 a 19 de novembro de 2009, na UNESP/Marília-SP.

${ }^{2}$ Doutor em Filosofia pela Universidade Estadual de Campinas; Professor do Departamento de Filosofia e dos Programas de Mestrado em Filosofia e Mestrado em Direito Negocial na Universidade Estadual de Londrina; Pesquisador Associado do Núcleo Direito e Democracia do CEBRAP.
} 
1973, p. 7; HABERMAS, 1999b, p. 17-18). Com esse indicativo, a linha orientadora da teoria da evoluçáo social adquire relevância, ao servir de fundamento à teoria social, cujos alicerces delineados já em Técnica e Ciência como Ideologia (1968) encontrarão seu acabamento na obra magna de 1981, Teoria da Ação Comunicativa.

A teoria da evolução social - implicada na teoria social crítica - refere-se à dimensão histórica e social abordada por Habermas, a partir da reconstrução do materialismo histórico - dentro da tradição germânica que vai de Kant a Marx -, buscando assegurar inicialmente uma compreensão de filosofia da história empírica com intenção prática (MC CARTHY, 1979, p. ix) ${ }^{3}$. Desconsiderando a pretensão de uma filosofia da história que almeja o espectro contemplativo da história como um todo, não apenas em sua visão retrospectiva, mas também prospectiva, a qual visa a assegurar um progresso necessário firmado por pressupostos metafísicos provenientes de Deus, da natureza, da razáo ou do espírito, Habermas irá posicionar o estatuto da história como contingente em relação tanto às condiçôes empíricas quanto às mudanças que ocorrem na prática e no envolvimento dos agentes sociais. Com isso, ele retira toda hipostasiação metafísica da história para sinalizá-la sob outro foco de luz: o da projeção prática. "O futuro projetado (o qual confere significaçáo ao passado) não é um produto da contemplação ou da predição científica, mas de uma ocupação localizada da razão prática." (MC CARTHY, 1979, p. x).

Desse modo, a teoria social crítica não se limita à construção de uma teoria da evolução restrita à reconstrução do materialismo histórico, operando simplesmente na explanação retrospectiva de desenvolvimentos passados, mas, com base nesse suporte teórico, mantém, sobretudo, uma análise historicamente orientada da sociedade contemporânea com intenção prática, o que significa, conforme Mc Carthy, a reconstrução da crítica da sociedade capitalista (MC CARTHY, 1979, p. xxiii). A intenção de Habermas é conceber "[...] o processo formativo da sociedade como um todo, reconstruindo a situação contemporânea com a visão não somente do passado, mas também de antecipação do futuro. Isto será a teoria crítica da sociedade." (MC CARTHY, 1979, p. xvi).

Os trabalhos de Habermas na década de 1970 priorizaram, principalmente, duas frentes de pesquisas. De um lado, o empreendimento pelos fundamentos da racionalidade comunicativa objetivando recompor o fôlego normativo da teoria crítica, e, por outro, a construção de uma teoria

\footnotetext{
${ }^{3}$ A esse respeito, ver ainda REPA, 2004, p. 306.
} 
de evolução social, tendo em vista dar conta "[...] do desenvolvimento das estruturas normativas da consciência e de seu influxo na configuração histórica das sociedades." (OLMOS, 1991, p. 174).

Em Para a Reconstrução do Materialismo Histórico, publicado em 1976, Habermas aponta que as estruturas de racionalidade integradas à ação comunicativa emergiram como possibilidade de serem visualizadas e manifestas nas imagens de mundo, nos mecanismos de resolução consensual de conflitos e na formação das identidades. O próprio mecanismo normativo, presente nas estruturas de racionalidade e encarnadas na cultura, na sociedade e na personalidade, é quem sustenta, segundo Habermas, a possibilidade de o desenvolvimento da evolução social se efetivar na formação de novos princípios de organizaçẫo $o^{4}$ orientados por novas formas de interpretação social, que serviráo de base para suportar o aumento da complexidade sistêmica e a implementação de novas forças produtivas. Pode-se afirmar que, em Para a Reconstrução do Materialismo Histórico, Habermas concebeu os passos iniciais para assegurar a conexão entre teoria da comunicação e teoria da evolução social. Porém, as amarraçóes buscadas por ele para garantir tal vínculo não foram suficientes, naquele contexto (OLMOS, 1991, p. 179). Na Teoria da Ação Comunicativa, publicada em 1981, ocorrerá, por outro caminho, a integração dessas duas linhas de investigaçôes, e a racionalidade comunicativa, mais bem amadurecida, servirá de fio condutor para a explicação, via evolução social, da gênese da modernidade, sobretudo por intermédio da racionalização das imagens de mundo, da formalização dos parâmetros normativos e da formação reflexiva da identidade (OLMOS, 1991, p. 174).

Desde a distinção entre trabalho e interação, aventada já em 1967, está posta a ideia de que a constituição e a realização da espécie humana baseiamse em dois momentos distintos que contemplam a reprodução material

\footnotetext{
${ }^{4}$ Os princípios de organização são os responsáveis pela determinação da formação social e também retêm em si, enquanto espaço "abstrato", as possibilidades de mudança social. Habermas tece uma ampla consideração sobre os princípios de organização, em Problemas de Legitimação do Capitalismo Tardio, a qual merece destaque: "Por 'princípios de organizaçáo' entendo ordenamentos de índole muito abstrata que surgem como propriedades emergentes em saltos evolutivos não prováveis e que em cada caso caracterizam um novo nível de desenvolvimento. Os princípios de organizaçáo limitam a capacidade que uma sociedade tem de aprender sem perder sua identidade. De acordo com esta definiçáa os problemas de auto-controle geram crises se (e só se) não podem ser resolvidos dentro do campo de possibilidade demarcado pelo princípio de organização da sociedade. Princípios de organização desse tipo estabelecem, em primeiro lugar, o mecanismo de aprendizagem de que depende o desprendimento das forças produtivas; em segundo lugar, determinam o campo de variação dos sistemas de interpretação garantidores da identidade. Por último, estabelecem os limites institucionais do aumento possível da capacidade de auto-controle". (HABERMAS, 1973, p. 18-19; HABERMAS, 1999b, p. 30).
} 
e a reprodução simbólica, seguindo etapas de desenvolvimento social até a consecução de níveis pós-convencionais de interação social e de realização da identidade pessoal (OLMOS, 1991, p. 178).

A reconstrução da história do gênero humano, em Marx, orientou-se pela alteração sucessiva dos modos de produção marcados por uma dinâmica evolutiva resultante da dialética entre forças produtivas e relaçôes de produçáo. A partir da distinção entre dinâmica e lógica evolutiva ${ }^{5}$, proposta por Habermas, foi possível classificar a reconstrução histórica de Marx como resultado único e exclusivo da dinâmica evolutiva, portanto, uma reconstruçáo unilateral.

Marx situa o motor do desenvolvimento social no incremento das forças produtivas, isto é, no nível do que Habermas denomina ação racionalteleológica ou ação estratégica, em que os sujeitos (atores enfrentados na ação estratégica) seguem máximas decisórias determinadas para si mesmas em monólogo. Trata-se, pois, de processos de aprendizagem situados em uma dimensão puramente objetivante, no qual a racionalização depende da acumulação de conhecimentos verdadeiros, porém não implica necessidade de veracidade nem de conformidade a um contexto normativo, isto é, de consenso. (OLMOS, 1991, p.180).

Para ampliar o foco de reconstrução do materialismo histórico, Habermas substituiu a relação dialética presente em Marx por duas dimensóes de aprendizagem que contemplam tanto o conhecimento técnico quanto a consciência prático-moral. A concepção de aprendizagem situada na ação comunicativa, mais especificamente na dimensão prático-moral, implicou normas de validade intersubjetiva conectadas por expectativas recíprocas de comportamento. A capacidade de aprendizagem nesse contexto permite a orientação de práticas de interaçóes que se desdobram e se aperfeiçoam em sintonia com o desenvolvimento da consciência moral. Portanto, nesse ponto em específico reside para Habermas o motor e, ao mesmo tempo, o elemento balizador da evolução social. A mudança de foco em relação à dialética de Marx fez ainda que Habermas reformulasse o conceito de modo de produção, tornando-o mais abstrato no conceito de princípio de organização, conceito este que servirá de lócus institucional para a aprendizagem e para avaliação do

\footnotetext{
${ }^{5}$ A relação entre sistema e mundo da vida, quanto à evolução social, levou Habermas a estabelecer a diferenciaçấo entre dinâmica evolutiva e lógica da evolução para escapar das premissas de uma filosofia da história e evitar que o escopo da evolução social ou se limitasse a aspectos contingentes de ordem histórica e material, ou se desprendesse do empírico, perdendo-se no vazio da abstração (VILLACANAS, 1989, p. 184).
} 
nível de aprendizagem que determinada sociedade ocupa dentro da lógica do desenvolvimento (OLMOS, 1991, p. 181). ${ }^{6}$

Enfim, Habermas amplia a noção de racionalidade, considerando-a em duplo sentido: a racionalidade instrumental e estratégica, que é aplicada à base material da sociedade, por um lado; e a racionalidade comunicativa, que é incorporada no nível da integração social, por outro. Os modelos de racionalidade são transladados, ao lado das tipologias de ação, para as sociedades. Nesse sentido, a compreensão e a classificação das sociedades baseiam-se tanto no nível de produção quanto no nível de integração social (HELLER, 1997, p. 312). Essa duplicação se fez necessária, de acordo com Habermas, para não se incorrer na limitação imposta por Marx, ao reduzir a sociedade ao nível de sua base exclusivamente material.

Habermas dá destaque à complexidade da configuração das sociedades modernas, fazendo a exigência de um conceito igualmente complexo de racionalidade que dê conta das esferas da coordenação de açôes, da integração social e da socialização. Contudo, o que procura garantir com firmeza é o fato de que, quanto mais complexo seja o modo de produção, tanto mais elevado é o sistema de integração social. Mesmo considerando que os processos de aprendizagem estão presentes em ambas as esferas de racionalidade, não deixa de ponderar que é tão somente o aprendizado acumulado na estrutura da dimensão prático-moral, com sua lógica própria, que possibilita a implementação de um novo modo de produção, ou melhor, um novo princípio de organização (HELLER, 1997, p. 313).

No âmbito da Teoria da Açáo Comunicativa, Habermas procura estabilizar o desenvolvimento individual e sociocultural pelo caminho da comunicação mediada linguisticamente. ${ }^{7}$ Desse modo, encontrar outro

\footnotetext{
${ }^{6}$ Por um lado, é bastante claro que a pretensão de Habermas é evitar o reducionismo de questôes práticas a questốes técnicas, reducionismo que ele vê manifesto em Marx. Porém, por outro lado, cabe questionar se a interpretação que Habermas faz do conceito de trabalho de Marx já não é por si própria reducionista. Havendo acerto na leitura de Habermas, acresce ainda contra Marx a crítica de que, apesar de seu interesse essencialmente prático na promoção do progresso humano, sua reflexão acabou por sucumbir ao saber empírico analítico, elevando o caráter utópico e visionário de sua teoria social ao quadrante puramente científico. A esse respeito, conferir: POPPER, Karl. A Sociedade aberta e seus inimigos. Belo Horizonte: Itatiaia; São Paulo: Edump, 1987, p. 88-96; e HABERMAS, Jürgen. Conhecimento e Interesse. Introdução e Tradução de José N. Heck. Rio de Janeiro: Zahar, 1982.

${ }^{7}$ STRYDOM, Piet. The Ontogenic Fallacy: The Immanent Critique of Habermas' Developmental Logical Theory of Evolution. In: Theory, Culture \& Society: Explorations in Critical Social Science. Vol. 9, number 3, August/1992. p. 307. ["Doubt is also expressed as to whether a structural similarity could be established between individual and sociocultural development by way of linguistically mediated communication".]
} 
caminho para a relação ontofilogenética, diferente daquele praticado em Para a Reconstrução do Materialismo Histórico, uma vez que, nessa obra, como sugerem muitos críticos, Habermas teria sucumbido à falácia ontogenética (ontogenetic fallacy) - que se refere à transferência da estrutura da lógica do desenvolvimento ontogenético para a cultura e a sociedade como um todo constitui uma tarefa árdua para os propósitos da ação comunicativa.

Assegurar a relação ontofilogenética sem incorrer na falácia ontogenética exige de Habermas a manutenção de alguns pontos já desenvolvidos no projeto inicial da teoria da evolução social. Daqueles esboços esquemáticos da década de 1970, dois pontos são transladados para a Teoria da Ação Comunicativa: (i) o conceito de aprendizagem e (ii) a dialética entre forças produtivas e relações de produção de Marx. É notável que, na obra magna de 1981, Habermas não se desfaz completamente da dialética marxista entre forças produtivas e relaçóes de produção, porém, mantém a ideia de que os aumentos de complexidade dependem, por sua parte, da diferenciação estrutural do mundo da vida.

Quando se elege a institucionalizaçáo de níveis de diferenciaçáo sistêmica como elemento distintivo das correspondentes formaçōes sociais, o resultado é um paralelismo com os conceitos marxistas de base e superestrutura. Os impulsos para uma diferenciaçáo do sistema social procedem do âmbito da reproduçáo material. Portanto, podemos entender como "base" o complexo institucional que ancora no mundo da vida o mecanismo sistêmico que se faz em cada caso com o primado evolutivo, e que com ele circunscreve as possibilidades de aumento de complexidade em uma determinada formação social. O que resulta tanto mais lógico se com Kautsky interpretamos a distinçáo entre "base" e "superestrutura" na perspectiva da evolução social. (HABERMAS, 1981, II , p. 251; HABERMAS, 2003, II, p. 237).

O que se destaca desse contexto é uma correlação entre desenvolvimento do nível sistêmico e evolução social decorrente da racionalização do mundo da vida, sem, no entanto, abrir mão da dialética entre forças produtivas e relaçóes de produção (OLMOS, 1991, p. 196). Em linhas gerais, a teoria da evolução social, internamente (do ponto de vista da teoria), se firma diante da costura das obras de Habermas amparada, sobretudo, pelo dinamismo das estruturas normativas. Contudo, externamente (do ponto de vista histórico), a evolução social permanece alvo certo de críticas.

Dois fatores interligados são atualmente responsáveis pela falta de confiança nas teorias de evoluçáo social. Por um lado, a perda da crença no 
progresso, o que inevitavelmente gera ceticismo quanto às grandes narrativas da história, e, por outro, o pós-modernismo, que corrobora a insustentabilidade dessas narrativas (GIDDENS, 1991a, p.14). Porém, os posicionamentos críticos em relação à evolução social devem, antes de tudo, desconstruir qualquer possibilidade de a história ser entendida como uma unidade ou de refletir certos princípios unificadores de organização e transformação. É interessante, nesse caso, que aqueles que se póem favoráveis à corrente pósmoderna devam sustentar, antes de tudo, a consciência da pós-modernidade ou do que ela seja, ou ao menos a transição da modernidade a esse outro patamar de referência. "Falar da pós-modernidade como suplantando a modernidade parece invocar aquilo mesmo que é (agora) declarado impossível: dar alguma coerência à história e situar nosso lugar nela”. (GIDDENS, 1991a, p. 53).

Habermas, no entanto, em sua defesa de uma modernidade inacabada, fruto da incompletude da realização dos ideais do iluminismo, não obsta à possibilidade de um olhar atento ao desdobramento dos fatos históricos e, ainda, levado pela necessidade de oxigenar a teoria crítica a partir de "diagnóstico do presente", se vê impelido a sustentar, sem apelos à teleologia ou à metafísica, uma teoria de evolução social. Sem a evolução social não é possível considerar sequer uma teoria da modernidade, como o fez na esteira de Hegel, contemplada enquanto "consciência de época". Segundo o próprio Habermas, foi Hegel quem possibilitou tornar "[...] explícita a teoria da modernidade, que estava apenas delineada no conceito kantiano de razáo, e desenvolvê-la em uma crítica das divisôes de uma modernidade em conflito consigo própria”. (HABERMAS, 1989a, p. 21). ${ }^{8} \mathrm{O}$ aspecto de destaque em Hegel, conforme registrado em O Discurso Filosófico da Modernidade, é que esse autor foi o primeiro a tornar possível que a filosofia se reconhecesse a si própria como pensamento da sua época, o que permitiu elevar a história contemporânea a um nível de reflexão filosófica (HABERMAS, 2002, p. 73). Hegel atentava à consciência histórica moderna, ou seja, à consciência da sua própria época como problema filosófico que exigia da filosofia uma tarefa onerosa: a autocertificação dessa época, o que constituiu o problema filosófico da modernidade, já que "[...] a modernidade não pode e não quer continuar a ir colher em outras épocas os critérios para a sua orientação, ela tem que criar

\footnotetext{
${ }^{8} \mathrm{~A}$ esse respeito, ver ainda: BANNWART JÚNIOR, Clodomiro José. Modernidade e o novo lugar da Filosofia: a idéia de Reconstrução em Habermas. Mediaçôes: Revista de Ciências Sociais - Sociedade e Literatura. Londrina: v. 10, n. 01, p. 185-200, jan/jun., 2005.
} 
em si própria as normas por que se rege. A modernidade vê-se remetida para si própria sem que a isso possa fugir." (HABERMAS, 2001, p. 12). ${ }^{9}$

\begin{abstract}
Nesse contexto, é preciso lembrar que o tema da autocertificação não é localizado simplesmente no idealismo alemão, mas determina igualmente o pensamento de Habermas. Extrair critérios internos às formas modernas, sem, no entanto, recorrer às formas históricas particulares, é uma exigência que toca nos fundamentos normativos da teoria crítica. Habermas nem pode apelar para uma crítica imanente de tipo marxista ou hegeliano, uma vez que a consciência burguesa se torna cínica e instrumentaliza seus próprios ideais, nem pode buscar um critério imparcial em juízos normativos sem lastro na realidade. (REPA, 2000, p. 86).
\end{abstract}

A questão posta exige que a teoria social crítica seja orientada por meio de fundamentos normativos, os quais são alcançados na teoria da ação comunicativa. Com base no pressuposto comunicativo, Habermas, sem se desvencilhar da necessidade do diagnóstico do tempo presente, projeta a possibilidade segundo a qual somente na base de uma teoria da açáo [comunicativa] é possível realizar um diagnóstico exaustivo das sociedades contemporâneas (BERGER, 1991, p. 171). A ação comunicativa comunga de condiçôes "críticas" e, ao mesmo tempo, de condiçóes favoráveis à realização de "diagnóstico do tempo presente". Projetar a partir da teoria da ação tais condiçóes no seio de uma teoria social crítica significa, num primeiro momento, inscrever a racionalidade da ação na prática quotidiana do mundo da vida e, num segundo, projetar uma teoria de evolução social situada na própria base da teoria crítica da sociedade. O primeiro pressuposto é mais fácil de ser assegurado, ao passo que o segundo passa pela defesa de um possível progresso universal contido nas sociedades e nas instituiçóes, que possibilita a compreensão moderna de mundo sob parâmetros igualmente universais. Nesse sentido, a teoria da evolução social deve contribuir para os pressupostos de crítica e de diagnóstico do tempo presente, sem prescindir dos conteúdos normativos e sem distanciar-se demasiado dos conteúdos empíricos, sob pena de fazer acordar os sonhos altissonantes da filosofia da história.

Enquanto as sociedades pré-modernas mantinham a tradição como "[...] um modo de integrar a monitoração da ação com a organizaçáo tempoespacial da comunidade", as sociedades modernas se reorganizaram em

\footnotetext{
${ }^{9}$ Ver também, a esse respeito: HABERMAS, Jürgen. A nova intransparência: a crise do Estado de bemestar social e o esgotamento das energias utópicas. Tradução de Carlos Alberto Marques Novaes. Novos Estudos Cebrap: São Paulo. no 18, p. 77-102, setembro/1987.
} 
torno de um processo de reflexividade da vida social " [...] constantemente examinadas e reformadas à luz de informação renovada sobre estas próprias práticas, alterando assim constitutivamente seu caráter." (GIDDENS, 1991a, p. 45). Isso não implica desconsiderar que nas sociedades tradicionais não haja ocorrido mudanças e alteraçôes das práticas sociais, mas, principalmente, destacar que nas sociedades modernas se atingiu uma radicalização extremada no processo de revisão e de crítica de seus pressupostos e convençóes, o que faz crer que "[...] estamos em grande parte num mundo que é inteiramente constituído através de conhecimento reflexivamente aplicado, mas onde, ao mesmo tempo, não podemos nunca estar seguros de que qualquer elemento dado deste conhecimento não será revisado.” (GIDDENS, 1991a, p. 46).

Não obstante, na modernidade, a tradição perde o lugar privilegiado que dispunha nas sociedades pré-modernas, como mecanismo de coordenação das práticas sociais. Menos que pela tradição, as açóes sociais são permanentemente renovadas e reavaliadas mediante a apropriação dos conhecimentos que vão sendo produzidos sobre as próprias açôes e os sistemas sociais nos quais elas têm lugar. Isso não significa que a tradição desapareça; ela passa, contudo, a subordinar-se ao crivo da avaliaçáo reflexiva. (COSTA, 2006, p. 15).

A capacidade de autonomia de reflexão, seja do indivíduo, seja das sociedades pós-convencionais, parece contrastar com as evidências empíricas do cotidiano contemporâneo. Fazemos aqui menção a um questionamento de Sérgio Costa, dirigido à categoria de reflexividade de Beck e Giddens, que, sem querer forçar críticas externas ao próprio autor em questão, também serve a Habermas: "De que serve, por exemplo, constatar que se tornou mais reflexiva uma sociedade na qual a polícia perdeu o controle sobre a criminalidade e os cidadãos têm de estar permanentemente atentos à própria segurança?" (COSTA, 2006 , p. 22). Aqui se tem um problema, tendo-se em vista que a própria teoria da evolução social, conforme matizes estabelecidos na década de 1970, tende a projetar tanto o indivíduo como a sociedade num processo ascendente de autonomia, reflexão e criticidade, o que, inevitavelmente, é contrastado pela leitura dos fatos históricos produzidos principalmente a partir do século XX. ${ }^{10}$

\footnotetext{
${ }^{10}$ Considerando o texto A nova intransparência: a crise do Estado de bem-estar social e o esgotamento das energias utópicas, podemos nele ver a reflexão de Habermas sobre o esgotamento das energias utópicas, principalmente a utopia nutrida com base na sociedade do trabalho. O que se ressalta nesse texto é um olhar pessimista de Habermas diante dos fatos e acontecimentos históricos que marcam os tempos atuais. Diz ele: "As utopias clássicas traçaram as condiçôes para uma vida digna do homem, para a felicidade socialmente organizada; as utopias sociais fundidas ao pensamento histórico - que interferem nos
} 
Por isso, a questão é saber se a teoria da evolução social, sem abrir mão de pressupostos normativos, não giraria em falso no auxílio que concede à teoria social crítica quanto à realização do diagnóstico do tempo presente. Não seria essa teoria, em razão da impossibilidade de renunciar a pressupostos normativos oriundos da ação comunicativa, uma construção teórica desvinculada da dimensão empírica - entendendo-se por dimensão empírica os fatos sociais e o próprio desdobramento histórico - e, por esse motivo, altamente inflacionada de utopia? Ou seria a evolução social uma construção contrafactual que paira acima do empírico enquanto condição de possibilidade do julgamento dos níveis de desenvolvimento dos sistemas sociais?

A dificuldade de Habermas é conduzir a sua teoria da evolução enquadrada em pressupostos normativos e, ao mesmo tempo, manter aproximaçóes com o contexto empírico, porém, distanciando-se ao máximo do funcionalismo e evitando os respingos críticos que são dirigidos às teorias de evolução de modo geral.

Contudo, devemos ressaltar que a teoria da ação e da racionalidade comunicativa, sob a perspectiva sociológica - levando-se em conta a diferenciação das esferas culturais promovidas por Max Weber, a partir do pensamento de Kant - abriu condiçóes para compreender a modernidade fora de um possível paradoxo da racionalizaçáo ou de uma dialética da razão que

debates políticos desde o século XIX - despertam expectativas mais realistas. Elas apresentam a ciência, a técnica e o planejamento como instrumentos promissores e seguros para um verdadeiro controle da natureza e da sociedade. Contudo, precisamente essa expectativa foi abalada por evidências massivas. A energia nuclear, a tecnologia de armamentos e o avanço no espaço, a pesquisa genética e a intervenção da biotecnologia no comportamento humano, a elaboração de informaçóes, o processamento de dados e os novos meios de comunicação são técnicas de conseqüências intrinsecamente ambivalentes. E quanto mais complexos se tornam os sistemas necessitados de controle, tanto maiores as probabilidades de efeitos colaterais disfuncionais. Nós percebemos diariamente que as forças produtivas transformaramse em forças destrutivas e que a capacidade de planejamento transforma-se em potencial desagregador". (p.105) Se esse diagnóstico é indubitável e abre brechas para teorias que apontam um quadro desolador de dominação, opressão, irracionalidade e falta de perspectiva emancipatória, Habermas não pode desconsiderar tal realidade empírica em razão do potencial da racionalidade comunicativa movido pelo caráter emancipador da teoria da evoluçáo social em direçáo do mais alto grau de autonomia e de reflexão das sociedades pós-convencionais. O perigo que ronda a relação entre a teoria da evoluçáo social e a dimensão empírica é, sobretudo, a sobrevalorização da ação comunicativa quando comparada aos fatos sociais no desdobramento histórico, o que supóe um caminho unilinear e de mão única da racionalidade em direçáo à emancipação que opera normativamente sem o lastro empírico. Para Piet Strydom, a questão pode ser formulada do seguinte modo: Habermas não teria transformado a Dialética do Esclarecimento em uma teoria unilinear do progresso da razáo sem se preocupar com a dimensão empírica e/ou ideológica da modernidade? (cf. STRYDOM, 1993, p. 304-322). 
bloqueia a emancipação. Com a tese da seletividade ${ }^{11}$, Habermas faz notar que a crítica segundo a qual a racionalização conduz à deformação dos espaços vitais de socialização do mundo da vida, devido ao sobrepujamento do modelo de racionalidade com respeito a fins sobre a racionalidade comunicativa, não acarreta ao processo de racionalização determinar a priori, de forma necessária, o eclipsamento da extensão do agir comunicativo.

Não existe uma necessidade lógica, conceitual ou histórica de que os imperativos sistemáticos devam destruir o mundo vital. A dialética da ilustração sublinha em efeito o que é característico das sociedades contemporâneas industrializadas - as ameaças reais que se estabelecem na integridade comunicativa do mundo da vida. (BERNSTEIN, 1991, p. 46).

É manifesto que o processo de racionalização não contém em si uma lógica própria que gera, por consequência, as patologias da modernidade. Antes, ao contrário, a teoria da ação e da racionalidade comunicativa contempla uma lógica imanente de modernização (BERNSTEIN, 1991, p. 48). Essa ligação perdurável que Habermas buscou promover entre teoria da ação, teoria da racionalidade e teoria da modernidade justifica-se por duas razóes fundamentais: (i) Não há nada a inviabilizar a afirmação de que a construção histórica e real dos mundos da vida possa contemplar, ainda que apenas em expectativa, uma racionalizaçáo comunicativa dos espaços cotidianos geridos pela relaçáo de intersubjetividade. O diagnóstico teórico e crítico de Habermas indicou que o processo de racionalização produziu uma série de patologias na modernidade; no entanto, estas não bloqueiam a possibilidade de reivindicar a legitimidade de sistemas sociais ancorados no exercício pleno do agir comunicativo. (ii) A defesa de uma lógica inevitável no decurso da modernização levou Habermas a construir, do ponto de vista teórico - entenda-se teórico-reconstrutivista ${ }^{12}-\mathrm{o}$

\footnotetext{
${ }^{11}$ A tese da seletividade procura demonstrar que a dinâmica social e econômica da modernidade não corresponde à integralidade da lógica interna do processo de racionalização, conforme analisado por Weber. Segundo Luiz Repa, "[...] sem a perspectiva dada pela tese da seletividade, não se poderia ver como explicar a compreensão cognitivista do projeto moderno e ao mesmo tempo sua suplantaçáo por meio de uma reinterpretaçáo assentada em uma racionalidade complexa. Se o projeto não puder ser separado de alguma maneira de sua realizaçáo efetiva, o potencial racional da modernidade - e com ele suas projeçôes utópicas sobre uma vida emancipada - não poderia ser discernido da modernizaçáo burguesa enquanto tal. A partir da tese da seletividade, a modernização capitalista pode ser concebida como racionalizaçáo parcial. Mais: não há, como haveria em Weber, uma lógica inexorável que leve a uma dialética do esclarecimento culminando na perda de sentido e de liberdade". REPA, 2000, p. 38.

${ }^{12}$ A respeito de conceito de "reconstrução" em Habermas, ver REPA, Luiz. A transformação da filosofia em Jürgen Habermas: os papéis de reconstrução, interpretaçăo e crítica. 2004. Tese (Doutorado) Universidade de São Paulo, São Paulo, 2004 [Orientador Ricardo Terra].
} 
delineamento de uma teoria de evolução social que visa a assegurar aquilo que do ponto de vista do diagnóstico da modernidade náo foi inteiramente bloqueado: a expectativa da construção histórica de mundos da vida racionalizados sob a ótica da ação comunicativa; enfim, a aposta de que ainda "[...] existem fundamentos racionais de uma esperança social.” (BERNSTEIN, 1991, p. 49). Desse modo, a tarefa de Habermas consistiu em sustentar a reconstruçáo racional (vertical) da teoria da evoluçáo social, destacando no corpo da Teoria da Ação comunicativa, de maneira especial, aquilo que sobreviveu da estruturação do projeto inicial da teoria da evoluçáo social estabelecida nos anos setenta, ou seja, os processos sociais de aprendizagem. Afirma Bernstein: "Existe uma lógica da evolução social no sentido de que uma vez que se têm alcançado os processos sociais de aprendizagem de que já não podemos nos esquecer, a menos que consciente ou inconscientemente os reprimamos." (BERNSTEIN, 1991, p. 49). Habermas parece situar a possibilidade de a aprendizagem ocorrer mesmo a partir de catástrofes (HABERMAS, 2001, p. 65). Os fenômenos de violência e barbárie que marcaram o século $\mathrm{XX}$, sobretudo até os anos cinquenta, subtraíram as condições de uma orientação positiva e esclarecida da época. Mas, ainda assim, diz Habermas, será que não "[...] aprendemos algo a partir das catástrofes da primeira metade do século?" (HABERMAS, 2001, p. 60-61). Do potencial da aprendizagem resultam as condiçôes de otimismo mesmo diante de uma época bloqueada quanto aos caminhos que levam à emancipação. O quadro desolador de nossa constelaçáo histórica, do ponto de vista empírico, não é condição suficiente para decretar o abandono e o descrédito do potencial racional e emancipador da açáo comunicativa.

A ação comunicativa, nesse sentido, é uma tipologia formal de ação e sua inserção em nível metateórico não deixa de estar enraizada no mundo social, nas determinaçóes empíricas de cada espaço de organização social, porém, sem deixar relativizar as pretensôes de validade. É por intermédio da teoria da ação, em sentido amplo, que Habermas extraiu a tipologia da ação orientada ao entendimento e da ação orientada a fins, permitindo, por um lado, a distinção basilar de sua teoria da sociedade entre sistema e mundo da vida, e, por outro, a possibilidade de promover uma teoria de evolução social que vá além das limitaçóes de uma filosofia da história e do materialismo histórico de Marx. Os resultados que Habermas visou a alcançar com a sua teoria da ação comunicativa referem-se fundamentalmente ao "[...] esforço por manter a vigência e a validade de uma teoria crítica da sociedade no contexto do pensamento contemporâneo do pós-guerra”. (OLMOS, 1991, p. 183). 
A ação comunicativa possui o mundo da vida como dimensão complementar, pois é nesse solo "quase transcendental" que se misturam dois elementos importantes já destacados: linguagem e cultura. Todo procedimento que objetiva alcançar o entendimento "[...] requer como correlato um pano de fundo de linguagem e cultura dadas previamente e sem o que não seria possível a comunicação". (OLMOS, 1991, p. 189).

No projeto de Habermas, a teoria da ação conectada com a pragmática formal dos atos de fala se coloca como um modelo idealizado, de caráter meta-teórico, senão que também aspira a sua conexão com delineamentos empíricos, sobretudo, de tipo sociológico. A pragmática formal necessita da pragmática empírica para evitar idealizaçôes do conceito de ação comunicativa. (OLMOS, 1991, p. 190).

Aspecto significativo foi o fato de Habermas ter acrescentado à ação comunicativa, além de seu desempenho linguístico na transmissão de significado, compreensão e entendimento, também a capacidade de realização de interação social. Esse elemento constituiu fator preponderante que lhe possibilitou a construção de uma teoria da sociedade capaz de abordar desde a gênese e constituição das sociedades até a estruturação de uma teoria de evolução social com pretensôes de avaliar, nas diversas constelações históricas, o grau de desenvolvimento e/ou regressão social. A ação comunicativa exerce um papel básico e extremamente significativo na estruturação da evolução social, todavia, é fato notável que ela própria [ação comunicativa] e a teoria da evolução social mantêm um vínculo de circularidade, pois, à medida que a evoluçáo social se estrutura teoricamente, tendo por base a racionalidade comunicativa, é a teoria da evolução social que torna possível situar o desdobramento histórico da própria racionalidade comunicativa. Cabe ainda dizer que a teoria da evolução social não se ocupa apenas em apontar o grau de desenvolvimento social, mas igualmente em verificar e constatar quando determinado princípio de organização reprime as possibilidades de emancipação, permanecendo estagnado ou até mesmo regredindo em níveis de consciência, autonomia e reflexividade. Nesse sentido, o conceito de mundo da vida, arena da interação social, é a dimensão que melhor traduz o conceito de ação comunicativa para a extensão sociológica.

Assim, a teoria da sociedade em Habermas deve emanar da ação racional, contudo, de um conceito ampliado de ação que transcenda os limites da racionalidade meio-fim e permita entender o papel da ação comunicativa, seja 
na interação, seja na evolução social, sobretudo, pela tradição que remonta a Mead e Durkheim (BERGER, 1991, p. 167). Conforme Habermas destaca, em sua Teoria da Ação Comunicativa, o primeiro proporcionou uma elucidação da ontogênese a partir da estrutura simbólica das interaçóes, enquanto o segundo se ocupou da filogênese, recorrendo ao mecanismo de linguistização do sagrado como elemento formador da identidade coletiva. Ambas as interpretações são incorporadas por Habermas, que está atento mais ao caráter sistemático do que propriamente ao histórico das mesmas (OLMOS, 1991, p. 192).

Mead, concentrando-se na interação mediada simbolicamente, estabeleceu algumas distinções - gestos, sinais e fala diferenciada - que lhe possibilitaram demonstrar, num processo evolutivo, como ocorre o nascimento de formas comunicativas expressas linguisticamente na transposição de modelos de interaçôes mediadas por gestos para modelos de interaçôes mediadas por símbolos. O aspecto importante da análise de Mead que Habermas incorporou integralmente em sua reflexão é a concepção de que o indivíduo desenvolve a sua identidade (individuação) não de forma isolada, mas integrada socialmente. A consequência desse processo é a confirmação de que a personalidade se explica recorrendo necessariamente ao mundo social. Ademais, assegura-se, ainda com base na reflexão de Mead, outro elemento indispensável à teoria da ação habermasiana: a compreensão de que a interação simbólica não permite apenas o emprego comum de significados, mas abre caminho para a interação regida por normas. Porém, a fraqueza de Mead foi não ter esclarecido suficientemente a gênese do mundo social. Durkheim, por sua vez, serve de apoio no fornecimento de subsídios para uma reflexão mais polarizada na dimensão filogenética, o que certamente contribuiu para Habermas tematizar o conceito de identidade coletiva e sua vinculação às identidades individuais e, também, para a certificação de estruturas normativas baseadas inicialmente no sagrado, as quais serviram de fio condutor no esclarecimento da gênese normativa da ação comunicativa e da formação discursiva da vontade.

O núcleo da concepçáo habermasiana da identidade coletiva como intersubjetividade é tomado de Durkheim. A autoridade moral das normas sociais tem seu ancoramento no religioso. Na intersubjetividade, o consenso normativo é mediado de uma forma simbólica por tudo aquilo que promove culturalmente uma identidade coletiva. A modernidade inaugura a "linguistificaçáo" do sagrado [...] e desse modo, os fatores próprios do mundo da vida - reproduçáo cultural, integraçáo social e desenvolvimento da personalidade - passam a ser orientados pela força 
e propulsão da ação comunicativa, como decorrência do processo de racionalidade comunicativa. (LARA, 1990, p. 263-264).

O empreendimento de Habermas no quesito da evoluçáo social priorizou a demonstração de condiçóes estruturantes que apontam o desenvolvimento de novos níveis de integração social por meio da universalização e abstração das estruturas normativas da moral e do direito. Esse roteiro concede o "desencantamento do potencial de racionalidade da ação comunicativa”, propiciando que a razão comunicativa opere formalmente sem vínculos a condicionamentos empíricos e, ainda, conserva a separação entre ação orientada ao entendimento e ação orientada ao êxito que faculta o desacoplamento de sistema e mundo da vida, ponto fundamental para a "[...] reformulação da tese clássica da coisificação, estabelecida agora em termos de colonização do mundo da vida." (OLMOS, 1991, p. 196).

No entanto, cabe ainda dizer que a abordagem da teoria da evoluçáo social permanece aberta nos escritos da década de 1990, principalmente Direito e Democracia: entre facticidade e validade. Avançar até a constelação da década de 1990 significa abordar o vínculo entre teoria da sociedade e teoria do direito. Nessa nova constelação, a permanência da teoria social nos moldes estabelecidos na década de 1960 obriga-nos a questionar se ainda existe o vínculo desta com a teoria da evolução social ou se a presença significativa, nesse momento, da teoria do direito (e filosofia do direito) e da teoria política (e filosofia política) anulam o pressuposto evolutivo. Podemos, em princípio, afirmar que o papel desempenhado pelo direito, como elo de intermediação entre sistema e mundo da vida, não altera nem recoloca a questáo da homologia. Todavia, o que deve ser questionado é se Direito e Democracia mantém - e em que medida - a teoria da evolução social, principalmente no que concerne à extensão normativa (dimensão prático-moral: moral e de direito) e à contribuição desta, na consolidação de um Estado Democrático de Direito.

Em Direito e Democracia, Habermas adota uma nova concepção acerca do direito, ao indicar que a figura jurídica que alhures se opunha "[...] à força social integradora da comunicação converte-se aqui num meio da integraçáo social, assumindo a forma de coerção legitima do Estado." (HABERMAS, 1997 a, II, p. 325, posfácio). O novo posicionamento do direito na obra de Habermas se faz possível devido à constelação que reivindica a vinculação da teoria da sociedade com a teoria do direito apoiado no princípio do discurso (HABERMAS, 1997a, I, p. 24). A teoria do discurso assume contornos 
importantes tanto na ótica da teoria da sociedade quanto na perspectiva da teoria do direito. Pelo enfoque da teoria da sociedade, o direito ocupa-se de funçóes relativas à integração social. "Ele (o direito) funciona como uma espécie de correia de transmissão que transporta, de forma abstrata, entretanto, impositiva, as estruturas de reconhecimento recíproco existente entre conhecidos e em contextos concretos do agir comunicativo, para o nível das interaçóes anônimas entre estranhos, mediadas pelo sistema." (HABERMAS, 1997a, II, p. 308, posfácio). Nesse quesito, o direito exerce igualmente a função de estabilizar expectativas de comportamento, por meio da garantia de relaçóes simétricas entre titulares de direitos subjetivos. E pelo enfoque da teoria do direito, a teoria do discurso visa a alcançar um ponto de equilíbrio entre as teorias contratualistas - que concedem a autonomia dos indivíduos por meio do arbítrio privado em celebraçóes contratuais - e as teorias fortemente morais - que depositam na autodeterminação dos indivíduos "uma capacidade genuinamente moral." (HABERMAS, 1997a, II, p. 309, posfácio).

Para compreender a teoria da sociedade e a sua vinculação à teoria do direito por meio da teoria do discurso, há que se questionar o sentido específico que encerra a teoria da sociedade, em Direito e Democracia, além de recolocar a afirmação de Habermas, contida no prólogo de Problemas de Legitimação do Capitalismo Tardio, segundo a qual a teoria da evolução social deve constituir a base de uma teoria da sociedade. Em suma, deve-se responder até que ponto a teoria da sociedade, em sua conexão com a teoria do direito, leva adiante os pressupostos da evoluçáo social.

O pressuposto é que "[...] a evolução social na direção da modernidade está estreitamente vinculada à construção do Estado de direito" (MARTINS, 2005, p. 79). Habermas parece que tende a ler, no movimento da história, uma transformação e aperfeiçoamento do ordenamento jurídico. $\mathrm{O}$ dispositivo para esse processo evolutivo está assentado na ideia de aprendizagem social. "Devido às suas características formais, o direito positivo, que surge na modernidade como resultado de um processo de aprendizagem social, pode ser tomado como meio adequado para a estabilização de expectativas de comportamento; e parece não haver, nas sociedades complexas, um equivalente para ele". (HABERMAS, 1997a, II, p. 322). A colocação do Estado de Direito no foco central da reflexão habermasiana, a partir de Direito e Democracia, implica admitir que "[...] o direito aparece como uma realidade necessária, como um factum que não pode ser omitido no curso do processo de evolução social..." (MARTINS, 2005, p. 73). A questão, porém, é saber, em primeiro lugar, qual 
é o papel específico que a evolução social ocupa na arquitetura de Direito e Democracia; em segundo lugar, avaliar se a evolução social se mantém fiel aos pressupostos estabelecidos nas décadas anteriores. Mas isso já é assunto para outra oportunidade de pesquisa. $\mathrm{O}$ importante é registrar que o direito ocupa uma posição oscilante no pensamento habermasiano. $\mathrm{O}$ direito, seja como parte integrante das instituiçóes da sociedade (década de 1970), seja como elemento que integra sistema e mundo da vida (1990), possui nesses diferentes períodos uma dimensão que cristaliza o potencial de aprendizagem, destoando da experiência da década de 1980, período em que ele é compreendido como artifício de institucionalização da racionalidade instrumental, portanto, vinculado unilateralmente à dinâmica evolutiva.

Discorrer sobre a teoria da evolução social habermasiana permite destacar a importância e a integração dos diversos autores que compóem o grande mosaico da teoria da ação comunicativa. Nesse sentido, a contribuição de Weber foi conceder o lastro sociológico, enquanto diagnóstico de época, da indicação do modelo de sociedade em que estamos situados, ou seja, uma sociedade pós-convencional. Habermas se apropria de Weber para colocar sua teoria da ação comunicativa em uma base sociológica, o que significa a possibilidade de sedimentar uma visão empírica da sociedade pós-convencional, por intermédio do desacoplamento entre sistema e mundo da vida. O interesse sociológico visa o restabelecimento da crítica social, por intermédio de uma teoria social crítica que não seja relativista, mas assentada na universalidade da razão, e também para tratar da racionalidade apoiada mais num ponto de vista social do que transcendental (POSTONE, 1993, p. 243).

A sociedade pós-convencional dispóe da consciência de sua época em razão do caráter reflexivo que lhe é próprio. A reflexividade é condição inerente para a aprendizagem, e essa sociedade sabe que o seu desenvolvimento se baseia nessa capacidade. Com Mead foi possível a Habermas perceber que o desenvolvimento e a capacidade da aprendizagem individual só se realizam coletivamente. E, com Durkheim, colhe-se o indicativo de que, nesse modelo de sociedade pós-convencional, a integração social depende igualmente de um padrão de aprendizagem pós-convencional, isto é, construído na tematização discursiva das pretensóes de validade. Para finalizar, Piaget e Kohlberg - o pano de fundo do mosaico - serviram de suporte para colocar a teoria e a história da ação comunicativa na dimensão estrutural da lógica do desenvolvimento. 
BANNWART JÚNIOR, Clodomiro José.The evolutionary perspective in Habermas' critical social theory. Trans/Form/Ação, Marília, v. 36, p. 67-86, 2013. Edição Especial.

\begin{abstract}
We seek to follow the development of evolutionary theory in the thought of Habermas, starting with the statement taken from the Prologue of Legitimation Crisis, 1973: "The programmatic character of Part I of this book makes clear that a theory of social evolution, although it must be the basis of social theory, is today still scarcely at all developed." Attention is directed to how Habermas reorients the evolutionary meaning of historical development in light of the concept of lifeworld as the sphere of the realization of communicative action. We seek to investigate how Habermas' model assigns, by means of language, the task of symbolic production and reproduction of the normative consensus among participants in the social world, while at the same time indicating that there is a telos of social integration immanent in the communicative practice itself. In this sense, we seek to demonstrate that just as universal pragmatics serves as the theoretical basis for the analysis of processes of abnormal socialization and the distortion of language, the theory of social evolution serves as a parameter for a critical social theory with the emancipatory intent of evaluating the empirical and contingent unfolding of historical dynamics.
\end{abstract}

KEYWORDS: Social evolution. Communicative action. Social integration. Social theory.

\title{
REFERÊNCIAS
}

BANNWART JÚNIOR, Clodomiro José. Modernidade e o novo lugar da Filosofia: a idéia de Reconstrução em Habermas. Mediaçôes: Revista de Ciências Sociais - Sociedade e Literatura. Londrina: v. 10, n. 01, p. 185-200, jan/jun., 2005.

BERGER, Johannes. The Linguistification of the Sacred and the Deslinguistification of the Economy. In: HONNETH, Axel; JOAS, Hans (Ed.). Comunicative Action. Essays on Jürgen Habermas's The Theory of Communicative Action. Translated by Jeremy Gaines and Doris L. Jones. Cambridge: Polity Press, 1991.

BERNSTEIN, Richard J. Introdução. In: GIDDENS, A. et al. Habermas y la modernidad. Tradução de Francisco Rodríguez Martín. Madrid: Cátedra, 1991, p. 13-61.

COSTA, Sérgio. Dois Atlânticos. Teoria Social, anti-racismo, cosmopolitismo. Belo Horizonte: Editora UFMG, 2006.

GIDDENS, Anthony. As Conseqüências da Modernidade. Tradução de Raul Fiker. São Paulo: Editora Unesp, 1991a.

GIDDENS, Anthony. Razón sin revolución? La Theorie des Kommunikativen Handelns de Habermas. In: GIDDENS, Anthony et al. Habermas y la Modernidad. Traduçáo de Francisco Rodríguez Martín. Madrid: Cátedra, 1991b, p. 153-192.

HABERMAS, Jürgen. Teoria de la Acción Comunicativa. Crítica de la razón funcionalista. Versión castellana de Manuel Jiménez Redondo. 4. ed. Tomo II. Madrid: Taurus Humanidades, 2003. 
HABERMAS, Jürgen. O Discurso filosófico da Modernidade. Tradução de Luiz Sérgio Repa e Rodnei Nascimento. São Paulo: Martins Fontes, 2002.

HABERMAS, Jürgen. A Constelação Pós-Nacional. Ensayos Políticos. Tradução de Márcio Seligmann-Silva. São Paulo: Litera Mundi, 2001.

HABERMAS, Jürgen. Teoria de la Acción Comunicativa. Racionalidad de la acción y racionalización social. Tomo I. Madrid: Taurus Humanidades, 1999a.

HABERMAS, Jürgen. Problemas de Legitimación en el Capitalismo Tardio. Traducción de José Luis Etcheverry. Madrid: Cátedra,1999b (Colección Teorema).

HABERMAS, Jürgen. O Discurso Filosófico da Modernidade. Tradução Ana Maria Bernardo et al. Lisboa: Publicaçóes Dom Quixote, 1998.

HABERMAS, Jürgen. Direito e Democracia: entre facticidade e validade. Tradução de Flávio Beno Siebenscheiner. Rio de Janeiro: Tempo Brasileiro, 1997a.

HABERMAS, Jürgen. Técnica e Ciência como 'Ideologia'. Tradução de Artur Morão. Lisboa: Ediçôes 70, 1997b.

HABERMAS, Jürgen. Para a Reconstrução do Materialismo Histórico. Tradução de Carlos Nelson Coutinho. 2. ed. São Paulo: Brasiliense, 1990.

HABERMAS, Jürgen. Consciência Moral e Agir Comunicativo. Traduçáo de Guido A. de Almeida. Rio de Janeiro: Tempo Brasileiro, 1989a.

HABERMAS, Jürgen. Teoria de la Acción Comunicativa: complementos y estudios previos. Traducción de Manuel Jiménez Redondo. Madrid: Catedra, 1989b.

HABERMAS, Jürgen. A nova intransparência: a crise do Estado de bem-estar social e o esgotamento das energias utópicas. Tradução de Carlos Alberto Marques Novaes. Novos Estudos Cebrap: São Paulo. no 18, p: 77-102, setembro/1987.

HABERMAS, Jürgen. Conhecimento e Interesse. Introdução e Tradução de José N. Heck. Rio de Janeiro: Zahar, 1982.

HABERMAS, Jürgen. Theorie des Kommunikativen Handelns. Handlungsrationalität und gesellschaftliche Rationalisierung. Band 1. Frankfurt am Main: Suhrkamp, 1981a.

HABERMAS, Jürgen. Theorie des Kommunikativen Handelns. Zur Kritik der funktionalistischen Vernunft. Band 2. Frankfurt am Main: Suhrkamp, 1981b.

HABERMAS, Jürgen. Legitimationsprobleme im Spätkapitalismus. Frankfurt am Main: Suhrkamp Verlag, 1973.

HELLER, Agnes. Habermas y el marxismo. In: Crítica de la Ilustración: Las Antinomias Morales de la Razón. Traducción de Gustau Muñoz y José Ignacio López Soria. México: Península, 1997. 
KORTHALS, Michiel. On the justification of societal development claims. Philosophy \& Social Criticism: an international, inter-disciplinary quarterly journal. Vol. 19, no 1 . p. 2541, 1993.

LARA, Maria Pía. La Identidad Social em Habermas: entre el Consenso y la Alteridad. Revista Doxa. N. 07, p. 257-272, 1990.

MARTINS, Clélia Aparecida. A teoria do discurso na filosofia do direito de Habermas. In: PINZANI, A; DUTRA, Delamar V. Habermas em Discussão. Florianópolis: Nefipo, 2005, p. 69-79.

McCARTHY, Thomas. La Teoria Crítica de Jürgen Habermas. Tradução Manuel Jiménez Redondo. 2. ed. Madrid: Tecnos, 1992.

McCARTHY, Thomas. Translator's Introduction. In: HABERMAS, Jürgen. Communication and the Evolution of Society. Boston: Beacon Press, 1979.

OLMOS, Angel Prior. La Teoría de la Acción Social de J. Habermas. Revista de Filosofía. p. 173-196, 1991.

POPPER, Karl. A Sociedade aberta e seus inimigos. Belo Horizonte: Itatiaia; São Paulo: Edump, 1987.

POSTONE, Moishe. Time, Labor, and Social Domination. A reinterpretation of Marx's critical theory. Cambridge: Cambridge University Press, 1993.

REPA, Luiz. A filosofia como ciência reconstrutiva e as exigências da teoria crítica. In: PINZANI, Alessandro; DUTRA, Delamar Volpato. Habermas em Discussão. In: COLÓQUIO HABERMAS, UFSC - 30/03-01/04//2005. Florianópolis. Anais... Florianópolis: Nefipo, 2005, p. 11-19.

REPA, Luiz. A transformação da filosofia em Jürgen Habermas: os papéis de reconstrução, interpretação e crítica. 2004. Tese (Doutorado) - Universidade de São Paulo, São Paulo, 2004.

REPA, Luiz. Habermas e a Reconstrução do conceito Hegeliano de Modernidade. 2000. Dissertação (Mestrado) - Universidade de São Paulo, São Paulo, 2000.

STRYDOM, Piet. Sociocultural Evolution or the Social Evolution of Practical Reason?: Eder's critique of Habermas. Praxis International: A Philosophical Journal. Vol 13, no 3, p. 304-322, October/1993.

VILLACANAS, José L. Racionalización y evolución: Teoría e historia de la Modernidad en la obra de Habermas. Revista Ágora, p. 177-216, 1989. 